\title{
LASER RESONANCE IONIZATION MASS SPECTROMETRY FOR KRYPTON-81 ANALYSIS
}

\author{
B E LEHMANN*, H H LOOSLI*, HANS OESCHGER*, \\ DOMINIQUE RAUBER*, G S HURST**, S L ALLMAN**, \\ C H CHEN**, S D KRAMER**, NORBERT THONNARD + , \\ and R D WILLIS $†$
}

ABSTRACT. A new laser-based analytical technique is described for isotope selective noble gas atom counting. The method has been used to detect ${ }^{81} \mathrm{Kr}$ atoms in a groundwater sample.

\section{INTRODUCTION}

Krypton- 81 is a cosmic-ray produced radioisotope with a half-life of 210,000 years. Due to its inert chemical character and the fact that the atmosphere is the main reservoir with a concentration that has probably been constant for a long time, ${ }^{81} \mathrm{Kr}$ is an excellent candidate for dating groundwater and polar ice in the range of 50,000-1,000,000 years.

The concentration of ${ }^{81} \mathrm{Kr}$ in a modern water sample is only ca 1000 atoms/L, and therefore hundreds of tons of water would have to be degassed for a ${ }^{81} \mathrm{Kr}$ measurement by even the best low-level decay-counting techniques. Furthermore, the new tandem-accelerator-based atom counting systems cannot be used because krypton does not easily form negative ions.

An extensive effort has been undertaken at the Oak Ridge National Laboratory to develop an analytical method for counting noble gas atoms with isotope selectivity. The technique uses pulsed lasers to selectively ionize atoms according to atomic number $\mathrm{Z}$ by the process of Resonance Ionization Spectroscopy (RIS) and a small mass spectrometer to select the isotope according to mass number A.

One main goal of this development is a ${ }^{81} \mathrm{Kr}$-based solar neutrino flux measurement. In this paper we report on first ${ }^{81} \mathrm{Kr}$ measurements in natural groundwater samples.

\section{THE ${ }^{81} \mathrm{KR}$ DETECTOR}

The detector is basically a commercial quadrupole mass filter in a closed high vacuum chamber of ca 3L with optical windows through which light from various lasers is pulsed. Krypton atoms are affected by lasers in three ways (see Fig 1):

\section{Laser Annealing}

A krypton sample goes through an isotope enrichment procedure (see below) before final counting. At the end of this process, $\mathrm{Kr}$ atoms are implanted with $10 \mathrm{kV}$ into a high-purity silicon wafer which is then mounted onto the target wheel of the detector. When a short high energy pulse (eg, frequency-doubled Nd:YAG laser, $532 \mathrm{~nm}, 1 \mathrm{~J} / \mathrm{cm}^{2}, 10 \mathrm{nsec}$ ) is absorbed, the silicon surface melts to a shallow depth of ca $1 \mu \mathrm{m}$. As the crystal

* Physics Institute, University of Bern, Switzerland

** Oak Ridge National Laboratory, Oak Ridge, Tennessee

† Atom Sciences, Inc, Oak Ridge, Tennessee 


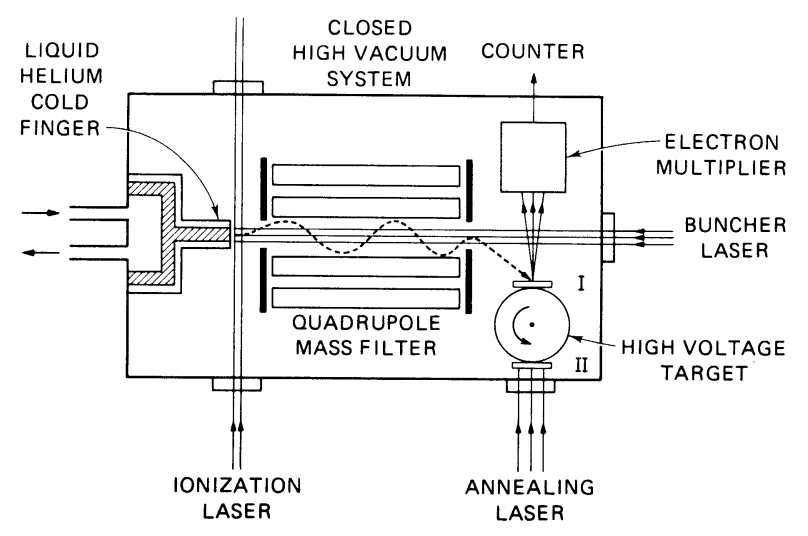

Fig 1. Schematic of the ${ }^{81} \mathrm{Kr}$ detector

reforms, the solid-liquid interface propagating back to the surface expels the stored $\mathrm{Kr}$ atoms back to the gas phase.

\section{Laser Bunching}

$\mathrm{Kr}$ atoms are then cryogenically trapped on a well-defined liquid helium-cooled cold spot in front of the entrance aperture of the mass filter. This area can be heated by a $1 \mu \mathrm{sec}$ pulse from a flashlamp-pumped dye laser, and as a consequence, $\mathrm{Kr}$ atoms are evaporated and pass in "bunches" through a region of space above the cold surface after a short flight time. Thus, it is highly probable that the atoms will be in a defined volume for laser ionization at the described time.

\section{Laser Ionization}

The key process in our technique is pulsed element-selective photoionization. Several non-linear optical processes, such as frequency-doubling, frequency-mixing, Raman-shifting, and four-wave-mixing, are used to generate up to $700 \mathrm{~nJ}$ per pulse at $116.5 \mathrm{~nm}$ to selectively excite $\mathrm{Kr}$ atoms from the ground state to a first excited state. A second resonant step at $558.1 \mathrm{~nm}$ promotes $\mathrm{Kr}$ atoms to a higher excited state, and ionization is completed by residual light of the Nd:YAG fundamental at $1064 \mathrm{~nm}$ (see Fig 2).

The $\mathrm{Kr}$ ions then pass the mass filter and are accelerated at the exit to $10 \mathrm{kV}$ to be implanted into a CuBe-target, where they trigger secondary electron emission. These electrons are monitored with a Johnston electron multiplier. In the process, the $\mathrm{Kr}$ ions are removed from the gas, not to be counted twice.

Full technical details on the laser system, the mass spectrometer, the buncher design, and the annealing procedure have been published (Hurst et al, ms).

\section{SAMPLE PROCESSING}

A krypton gas sample extracted from water cannot immediately be introduced to the detector because the ${ }^{82} \mathrm{Kr} /{ }^{81} \mathrm{Kr}$ ratio of $2.2 \times 10^{11}$ in a 
GRAND SCHEME FOR KRYPTON

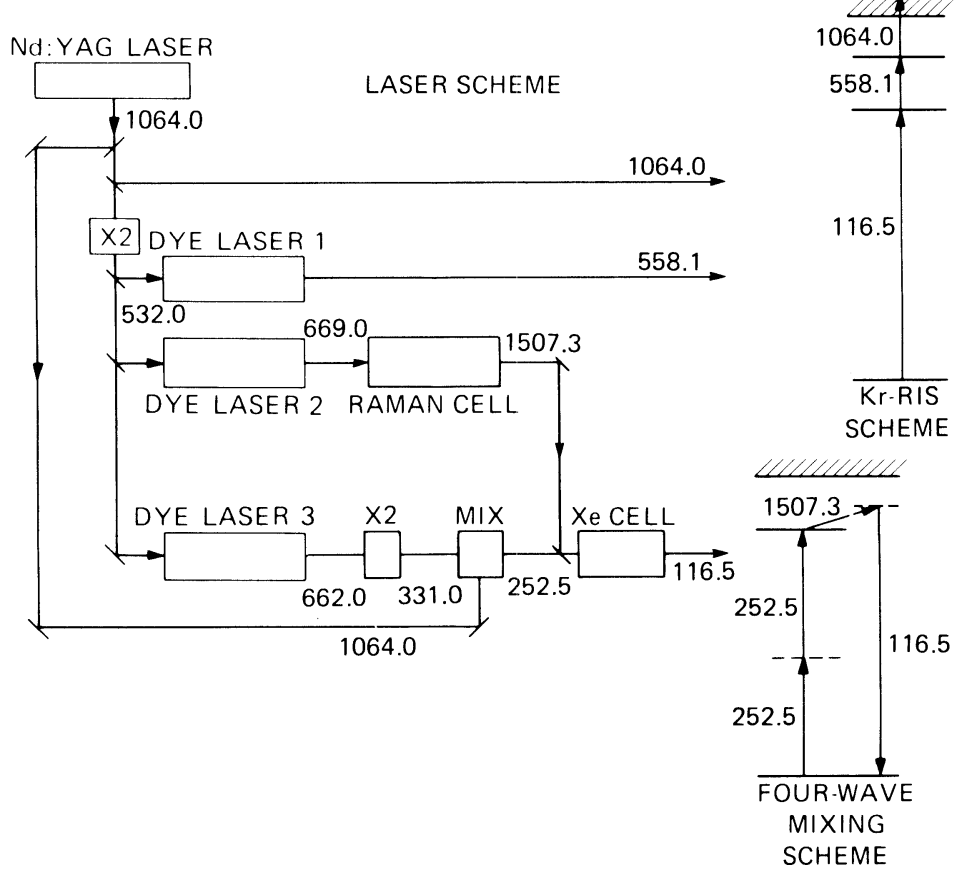

Fig 2. Resonance Ionization Spectroscopy scheme and method of generating wave length for krypton

natural modern krypton sample is too large to be resolved by the relatively simple quadrupole mass filter. The level of neighboring isotopes $\left({ }^{82} \mathrm{Kr}\right.$, ${ }^{80} \mathrm{Kr}$ ) must first be reduced by isotope enrichment.

The complete sample processing is outlined in Figure 3. Five steps are involved:

\section{Water Degassing}

Gas can be extracted from water by various methods, such as vacuum spraying, boiling, or helium gas bubbling, either in the field or from water samples taken into the lab. One requirement is that contamination with modern air is avoided during the sampling procedure.

\section{Krypton Separation}

At $10^{\circ} \mathrm{C} 1 \mathrm{~L}$ of air-saturated water contains $9.3 \times 10^{-5} \mathrm{cc}$ STP of krypton. From a water sample of $20 \mathrm{~L}$, we therefore expect up to $5 \times 10^{16}$ atoms of krypton including $2.6 \times 10^{4}{ }^{81} \mathrm{Kr}$ atoms. The separation of $\mathrm{Kr}$ from the extracted gases is achieved by gas chromatography and getter techniques.

\section{First Isotope Enrichment}

In this step we collect ca $5000{ }^{81} \mathrm{Kr}$ and reduce the level of interfering isotopes by 3 to 4 orders of magnitude. The $\mathrm{Kr}$ sample is introduced to a 


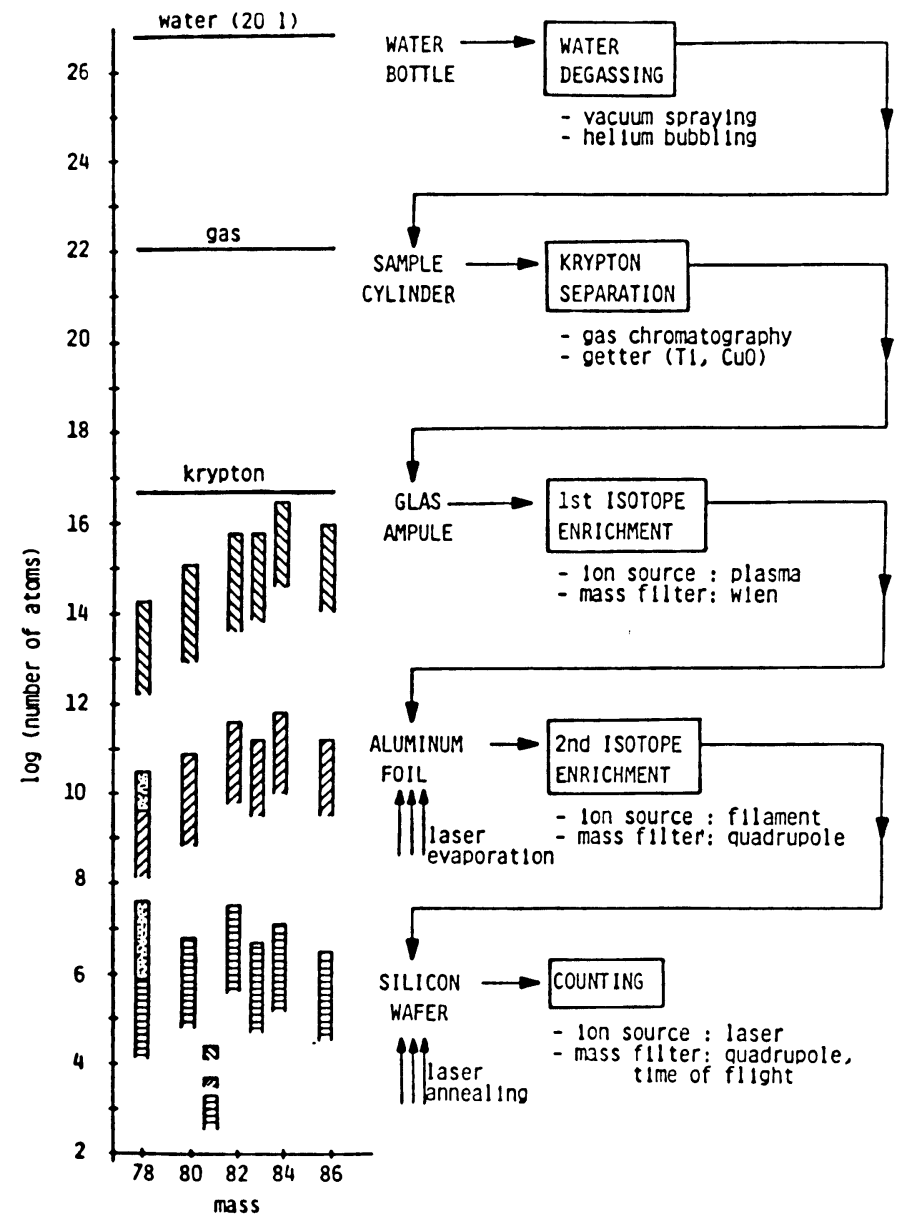

Fig 3. Sample processing for ${ }^{81} \mathrm{Kr}$ analysis of groundwater samples

closed vacuum system of ca $15 \mathrm{~L}$, where a titanium-zirconium getter pump maintains a pressure in the $10^{-7} \mathrm{mbar}$ range. A plasma discharge ion source produces $\mathrm{Kr}$ ions which are extracted, focused, and accelerated to $10 \mathrm{kV}$ to pass a commercial 6" Wien velocity filter (crossed E- and B-fields). After a flight pass of ca $150 \mathrm{~cm}, \mathrm{Kr}$ isotopes are spatially separated by ca $2 \mathrm{~mm}$ and can be sorted with an aperture arrangement, where ${ }^{81} \mathrm{Kr}$ atoms are implanted into an aluminum-coated kapton foil.

In order to work with small samples, the fraction of gas that is not ionized is pumped back to the source by a small turbomolecular pump. We maintain $3 \cdot 10^{-2} \mathrm{mb}$ in the discharge region and $2 \cdot 10^{-5} \mathrm{mb}$ in the drift tube in a closed mode of operation for several hours. Ca $20 \%$ of the initial $\mathrm{Kr}$ sample are actually used. 
Second Isotope Enrichment

A small piece $\left(8 \mathrm{~mm}^{2}\right)$ of aluminum-coated kapton foil containing ca 5000 atoms of ${ }^{81} \mathrm{Kr}$ and the remaining other stable isotopes, as indicated in Figure 3, is mounted onto a target wheel of the second isotope enrichment system, where $\mathrm{Kr}$ atoms can be released inside a high vacuum system by evaporating the aluminum coating with light from a frequency-doubled $\mathrm{Nd}$ :YAG laser. For the second enrichment step, $\mathrm{Kr}$ atoms are ionized by electron-impact, sorted by a quadrupole mass filter and implanted into a high-purity silicon wafer. $\mathrm{Ca} 40 \%$ of the ${ }^{81} \mathrm{Kr}$ atoms are collected, the interfering isotopes being reduced to levels indicated in Figure 3 .

\section{Counting}

As outlined in Section 2, the silicon wafer is introduced to the detector system, where $\mathrm{Kr}$ atoms are released by laser annealing. The abundance sensitivity of the quadrupole system, when operated with our laser-buncher ion source, can be as high as $10^{5}$ because ions are created with almost no initial energy in a well-defined region of space.

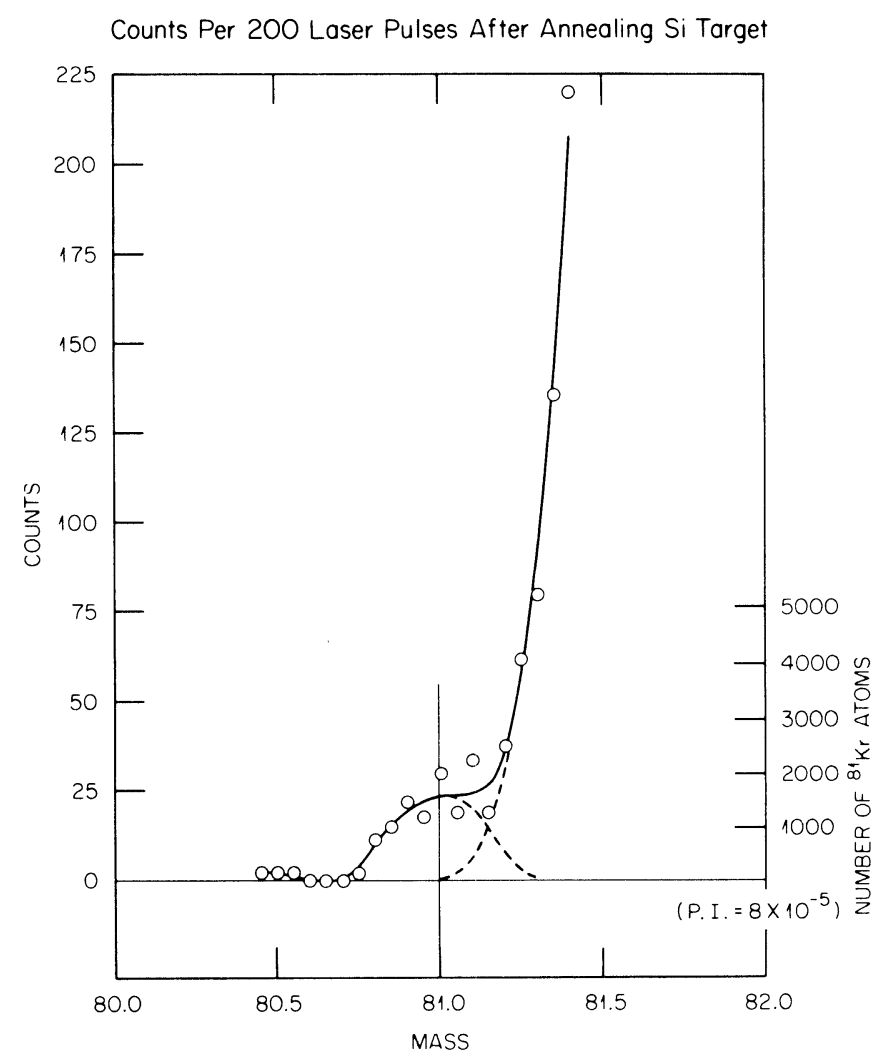

Fig 4. Counts per 200 laser pulses for a $\mathrm{Kr}$ sample extracted from ground water 
Figure 4 shows the mass spectrum of a first $\mathrm{Kr}$ sample that has been extracted from a real groundwater sample (Lehmann et al, 1985). The absolute number of ${ }^{81} \mathrm{Kr}$ atoms is based on an ionization probability per pulse of $8 \times 10^{-5}$ which was determined using a NBS ${ }^{81} \mathrm{Kr}$ standard gas.

\section{CALIBRATION}

The basis of a dating application has to be an isotope ratio measurement. We use ${ }^{78} \mathrm{Kr}$ as the reference isotope. It occurs in natural $\mathrm{Kr}$ with an abundance of $0.35 \%$; the modern ${ }^{78} \mathrm{Kr} /{ }^{81} \mathrm{Kr}$ ratio is therefore $6.0 \times 10^{9}$. In each isotope enrichment step, this ratio is reduced by a constant factor (eg, 500 ) by switching repeatedly for short time intervals from mass 81 to mass 78. The two transport materials (aluminized kapton; silicon wafer) therefore contain well-defined levels of ${ }^{78} \mathrm{Kr}$, well above the residual atom level of the corresponding enrichment phase as indicated by the dotted areas for mass 78 in Figure 3. The final $\mathrm{Kr}$ sample that is introduced to the detector contains $10^{7}-10^{8}{ }^{78} \mathrm{Kr}$ atoms, and ca $2000^{81} \mathrm{Kr}$ atoms (for a modern sample). From the measured ${ }^{78} \mathrm{Kr} /{ }^{81} \mathrm{Kr}$ ratio we can calculate the initial value in spite of losses in the implantation and recovery processes that may be difficult to control.

\section{REFERENCES}

Hurst, G S, Payne, M G, Kramer, S D, Chen, C H, Phillips, R C, Allman, S L, Alton, G D, Dabbs, J W T, Willis, R D and Lehmann, B E, (ms), Method for counting noble gas atoms with isotopic selectivity: Ms subm to Repts Progress in Physics.

Lehmann, B E, Oeschger, H, Loosli, H H, Hurst, G S, Allman, S L, Chen, C H, Kramer, S D, Payne, M G, Phillips, R C, Willis, R D and Thonnard, N, 1985, Counting ${ }^{81} \mathrm{Kr}$ atoms for analysis of groundwater: Jour Geophys Research, v 90, no. B13, p 11547-11551. 